\title{
To Compare the Efficacy of Positional Release Therapy and Muscle Energy Technique in the Management of Unilateral Upper Fibers of Trapezitis
}

\author{
Jyothi Seshan ${ }^{*}$, Senthil Selvam, Sundaram, Suberia S \\ School of physiotherapy, VELS Institute of Science Technology and Advanced Studies, Thalambur, Chennai, India
}

\section{Abstract}

Background: "A. Kumaresan, G. Deepthi” (2012) stated that Positional release therapy can be useful in the alleviating the neck pain and improving the functional ability. Richa Mahajan (2012) stated Muscle energy technique and static stretching were effective in alleviating the mechanical neck pain in terms of decreasing pain intensity and increasing active cervical range of motion. The study will be done for the unilateral upper fibers of trapezitis with positional release therapy and muscle energy techniques (Post isometric relaxation technique).

Aim: The aim of the study is to find the comparison of effectiveness in positional release therapy and muscle energy technique in subjects with unilateral upper fibers of trapezitis.

Objective: To evaluate the effectiveness of [PRT and MET (PIRT)] with Ultrasound in subjects with unilateral upper fibers of trapezitis.

Method and Intervention: It includes 30 patients with between 20-35 years. Based upon subacute with inclusive criteria the subjects will be convenient sampling method divided into groups A and B. Each group consists of 15 members. Group A treated with Ultrasound with PRT for 7 sessions per week and Group B treated with Ultrasound with MET (PIRT) for 3 sessions per week. Each groups treated for 2 weeks.

Outcome: Pain intensity to measure visual analog scale, cervical ROM to measure goniometer and functional ability to measure neck disability score.

Results: Statistical analysis done using paired "t" test showed that there is both groups shows significant difference from pre-test to post-test. Group with PRT shows more improvement in pain reduction, increase in ROM and improvement in functional ability when compared with MET.

Conclusion: This study concludes that PRT is more effective in relieving cervical pain, restoration of cervical ROM and prevent neck disability when compared with MET for unilateral upper fibers of trapezitis.

\section{Introduction}

Neck pain is a common problem in the general population with point prevalence between $10 \%$ and $15 \%$ in (2017) [1].

When compared with other musculoskeletal disorders of neck and upper extremity are increasing as seen by the most frequent identified in occupational disorders.

Neck muscle show a strong tendency to develop hypertonus and spasm working postures with the neck in extreme flexion increase the load movement three to four times on the neck muscles. Also working task that include continuous arm movement always generate a static load component on these muscle.

Trapezitis is an inflammatory pain arising from the trapezius muscle causing a severe neck spasm. The optimal seated work posture the upper trapezius static load level is $2 \%$ to $3 \%$ maximum voluntary contractions [1].

Elevation of the shoulder without raising the arm may increase the load level on the upper trapezius to about $20 \%$ maximum voluntary contraction [1].

Upper trapezius muscle is designed as postural muscle and it is highly susceptible to overuse. The pain is present even during rest and is aggravated by activity; it may be referred to other area from the site of primary degenerative. Passive range of motion may be restricted due to pain and protective spasm in antagonist groups of muscle

\section{Publication History:}

Received: June 07, 2020

Accepted: June 28, 2020

Published: June 30, 2020

\section{Keywords:}

Unilateral upper fibers trapezitis, Subacute, Ultrasound, PRT, MET recent studies hypothecated that the trapezitis pathogenesis result from the over loading and injury of muscle tissue leading and injury of muscle tissue leading to involuntary shortening of localized muscle fiber. The area stressed soft tissue receive less oxygen, glucose hence subsequently accumulates high level of metabolic waste product the end result of this event is the development of trigger point [2].

Upper fibers of trapezius initiated rotation of the clavicle to prepare for elevation of the shoulder gridle. Any position which place trapezius in a shortened state for a period time without rest may shorten the fibers and leads to discomfort and restricted.

Prolonged mobile conversation, particularly those which elevate the shoulder to hold the mobile, working from a chair set too low for the desk or monitoring terminal, playing musical instruments particularly for extended period of time can all shorten trapezius fibers creating muscle spasm.

"Corresponding Author: Dr. Jyothi Seshan, School of physiotherapy, VELS Institute of Science Technology and Advanced Studies, Thalambur, Chennai, India; E-mail: jyothiseshan@gmail.com

Citation: Seshan J, Selvam S, Sundaram, Suberia S (2020) To Compare the Efficacy of Positional Release Therapy and Muscle Energy Technique in the Management of Unilateral Upper Fibers of Trapezitis. Int J Phys Ther Rehab 6: 163. doi: https:// doi.org/10.15344/2455-7498/2020/163

Copyright: (C) 2020 Seshan et al. This is an open-access article distributed under the terms of the Creative Commons Attribution License, which permits unrestricted use, distribution, and reproduction in any medium, provided the original author and source are credited. 
Citation: Seshan J, Selvam S, Sundaram, Suberia S (2020) To Compare the Efficacy of Positional Release Therapy and Muscle Energy Technique in the Management of Unilateral Upper Fibers of Trapezitis. Int J Phys Ther Rehab 6: 163. doi: https://doi.org/10.15344/2455-7498/2020/163

Page 2 of 8

Physiotherapy may include modalities like ultrasound and other treatment such as exercise therapies in addition chiropractic techniques like positional release therapy and muscle energy technique (post isometric relaxation techniques).

Lawrence H. Jones (1995) invented Positional release therapy (PRT), is a manual technique that restores a muscle to its normal resting tone. Alignment of trigger points allow identification of hypertonic muscles that are placed in positioned that approximate the origin and insertion of the hypertonic muscle. The muscle spindle activation is inhibited therapy decreasing the amount of efferent impulses to the brain, this leads to ten efferent impulses were attempting to protect the muscle. By interrupting this pathway the patients muscle is allowed to relax and assume a normal resting tone. The process is completed by slowly and passively returning the patients to an automatically neutral position without firing of the muscle spindle.

MET was first described in 1948 by Fred Mitchell. Muscle energy technique (post isometric relaxation technique) is a direct technique originally developed. The purpose of this technique is to treat joint hypomobility (stiffness) and restore proper biomechanical and physiological function to the joints. Different patients position, are utilized to engage the restriction before asking the patient to perform an isometric contraction to pull the restricted segment into a new motion barrier. The isometric contraction is performed in a precisely controlled direction against a precisely controlled counterforce by the therapist. MET is effective for mobilizing restricted joints, relaxing hypertonic and spastic muscle as well as facilitating neuromuscular reorganization it is an appropriate technique for patient whose symptoms are aggravated by certain posture or bodily position. Each treatment session begins and ends with a screening technique to assess the outcome of the manual techniques.

\section{Methodology}

Study design: Experimental study.

Sampling technique: Convenient sampling.

Study setting: Heal therapy physiotherapy clinic in Adambakkam.

Study duration: 2 weeks.

Population of the study: It includes 30 patients with age between 20-35 years. Based upon subacute with inclusive criteria, the subjects will be convenient sampling method divided into 2 groups $\mathbf{A}$ and $\mathbf{B}$. Each group consists of 15 members. Group A treated with ultrasound with positional release therapy and Group B ultrasound with muscle energy technique (post isometric relaxation technique).

\section{Inclusion Criteria}

1. Upper fibers of unilateral trapezitis with neck pain and stiffness, along with trigger points.

2. Age between $20-35$ years

3. Both gender

4. Special test for upper trapezius strength test positive sign.

\section{Exclusion Criteria}

1. Disc pathology

2. Neurological disorders in cervical spine and radiculopathy
3. Degenerative lesions involving cervical spine
4. Fracture of neck and shoulder
5. Brachial plexus injury
6. Any upper neural lesion in cervical spine in both upper extremity.

\section{Outcome Measurements}

\section{Visual analog scale}

It was used to measure the pain.

The VAS is a $10 \mathrm{~cm}$ long horizontal line with polar descriptors of 'no pain' and 'worst pain' possible. A visual analog scale (VAS) was used to grade their level of neck pain. Subjects indicated their pain by placing a vertical line at the point that represented their current level of symptoms [3].

\section{Neck disability index score}

Neck Disability Index Questionnaire for functional disability: NDI scoring for all the 10 items were done by asking the subject to mark their ability to perform each of the 10 activities. The NDI was scored from $0-50$ points $(0-100 \%)$ in which higher scores correspond to greater levels of disability. Using this system, a score of 5-14 points (10-28\%) was considered to constitute mild disability, 15-24 points (30-48\%) was considered to constitute moderate disability, 25-38 points (50-68\%) was considered to constitute severe disability, and scores above 34 points (68\%) indicate complete disability [4].

\section{Goniometer for cervical range of motion}

\section{Flexion and extension}

1. Fulcrum: On the external auditory meatus.

2. Fixed arm: Perpendicular to the ground.

3. Movable arm: It is parallel to a marker placed between the patients' mandible.

\section{Lateral flexion}

1. Fulcrum: Over the spinous process of C7th vertebrae.

2. Fixed arm: Along the spinous process of thoracic vertebrae.

3. Movable arm: Along the midline of the neck upto the external occipital protuberance.

\section{Rotation}

1. Fulcrum: centre of superior aspect of head.

2. Fixed arm: aligned with acromion process.

3. Movable arm: aligned with tip of the nose.

\section{Positional Release Therapy}

\section{Location of tender point}

These tender points are located along the middle portion of the upper fibers of the trapezius. 
Citation: Seshan J, Selvam S, Sundaram, Suberia S (2020) To Compare the Efficacy of Positional Release Therapy and Muscle Energy Technique in the Management of Unilateral Upper Fibers of Trapezitis. Int J Phys Ther Rehab 6: 163. doi: https://doi.org/10.15344/2455-7498/2020/163

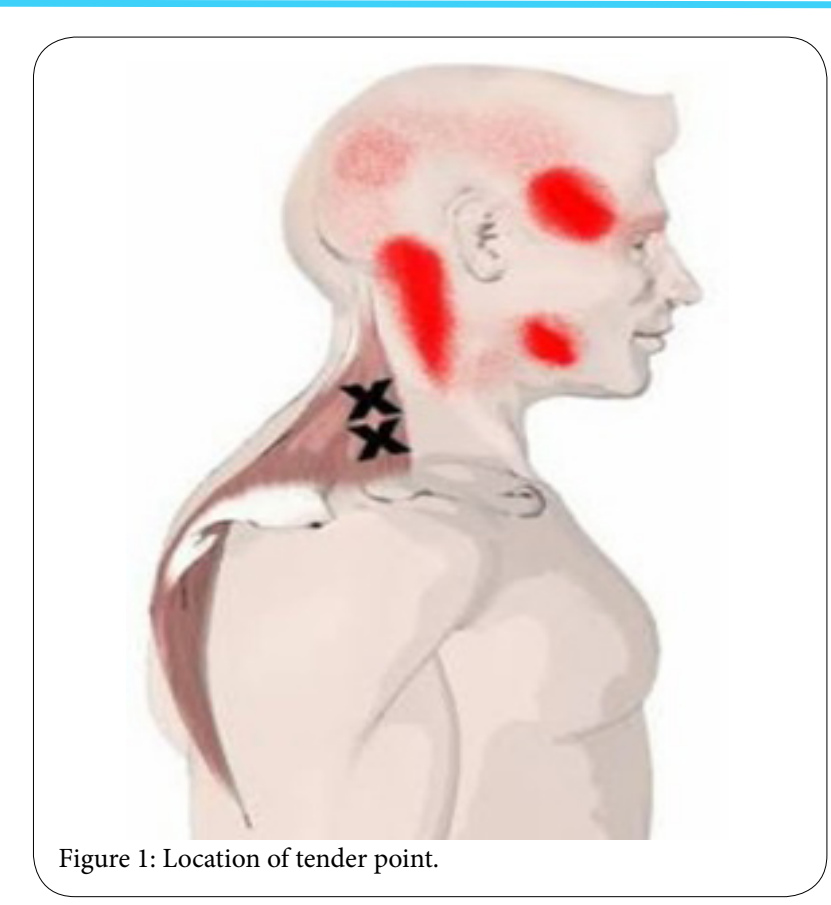

\section{Position of patient}

The patient is supine with the therapist standing on the tender point. The patient head is laterally flexed towards tender point side.

1. The therapist grasps the patients forearm and abducts the shoulder to approximately 90 and slight flexion to identify the upper fibers of trapezius in palpation.

2. Pressure is applied by pinching the muscle between the tip of the thumb and fingers.

3. Time duration 90 sec per section 2 times a day follow for 1 week [1].

\section{Ultrasound}

\section{Patient position}

Patient in sitting position, 90 angle in shoulder abduction.

\section{Instruction}

The patient should be comfortably seated with arm support.

Patient is asked to keep the part to be treated still and relaxed and to report any increase pain or other sensation immediately.

\section{Preparation of treatment part}

The couplant should be applied to the skin surface.

\section{Procedure}

1. The treatment head is moved continuously over the surface while even pressure is maintained in order to iron out the irregularities in the sonic field.

2. The emitting surface must be kept parallel to the skin surface to reduce reflection and pressed sufficiently firmly to exclude any air.
3. The pattern of movement can be a series of overlapping parallel strokes, circle of figures of eight [1].

Frequency: $3 \mathrm{MHz}$.

Mode: Continuous mode

Intensity: $1.7 \mathrm{~W} / \mathrm{cm}^{2}$.

Duration: 7-8 Minutes.

Sets: 1 times daily continue for 1 week.

\section{Muscle Energy Technique}

\section{Procedure}

Then the participant received MET directed towards the involved upper trapezius.

\section{Position of patients}

The participant was placed in supine lying position.

1. The therapist stabilized the shoulder on the affected side with one hand, while the ear/ mastoid area of the affected side was held by the opposite hand.

2. The head and neck was then bent towards the contralateral side, was flexed and rotated ipsilaterally placing the participant just short of their upper trapezius barrier.

3. Then the participant was asked to shrugged the involved/ stabilized shoulder towards the ear at a submaximal, pain-free, effort ( $20 \%$ of their available strength).

4. Then it was followed by further contralateral side bending, flexion, and ipsilateral rotation to maintain the soft tissue stretch was held for 30 seconds and was repeated three to five times per treatment session.

5. 3 sessions per week, holding time 30 seconds reptation to 10 [2].

\section{Data Analysis}

All statistical analysis was performed on IBM compactible micro computer using statistical package for the social sciences (SPSS 17.0).

\section{Result}

Both groups shows significant difference from pre-test to posttest. Group with PRT shows more improvement in pain reduction, increase in ROM and improvement in functional ability when compared with MET.

\section{Discussion}

In this study, stated as subjects receiving positional release therapy is relieve upper fibers of trapezitis than subjects receiving muscle energy technique (PIRT).

Based upon statistical analysis, there was significant difference between pre-test and post-test for both group $\mathbf{A}$ and $\mathbf{B}$ in treatment section for 2 weeks. It shows that both groups was taken pre and post an outcome measure was VAS where reduction in pain intensity, NDI questionnaire improvement in functional ability and Goniometer for cervical range of motion. 
Citation: Seshan J, Selvam S, Sundaram, Suberia S (2020) To Compare the Efficacy of Positional Release Therapy and Muscle Energy Technique in the Management of Unilateral Upper Fibers of Trapezitis. Int J Phys Ther Rehab 6: 163. doi: https://doi.org/10.15344/2455-7498/2020/163

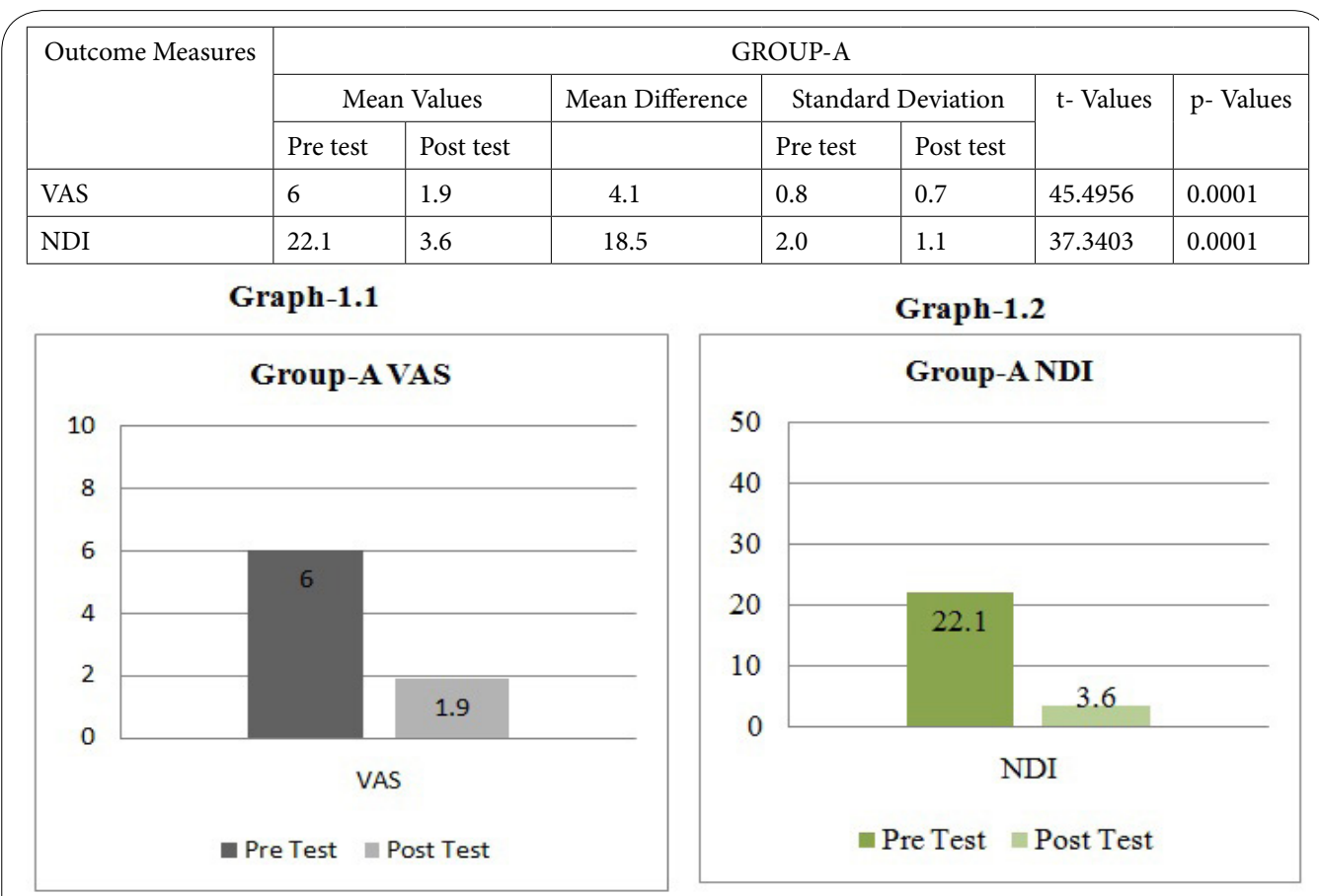

Table 1: Shows the significant difference between pre and post-test within Group A PRT. The paired " $\mathrm{t}$ " test shows VAS mean difference as 4.1 and is extremely statistically significant $(\mathrm{p}=0.0001)$. Mean difference for NDI score as 18.5 and is extremely statistically significant $(\mathrm{p}=0.0001)$.

\begin{tabular}{|l|l|l|l|l|l|l|l|}
\hline \multicolumn{7}{|c|}{ Outcome Measures } & \multicolumn{7}{|c|}{ GROUP-A } \\
\hline & \multicolumn{2}{|c|}{ Mean Values } & Mean Difference & \multicolumn{1}{|c|}{ Standard Deviation } & \multicolumn{2}{c|}{ t- Values } & p- Values \\
\hline & Pre test & Post test & & Pre test & Post test & & \\
\hline Flexion & 42 & 46.8 & 4.8 & 2.1 & 2.1 & 11.7979 & 0.0001 \\
\hline Extension & 48.7 & 52.7 & 4 & 1.4 & 1.5 & 16.7332 & 0.0001 \\
\hline Right Rotation & 61.3 & 65.2 & 3.8 & 1.9 & 1.9 & 16.3582 & 0.0001 \\
\hline Left Rotation & 61.1 & 64.7 & 3.6 & 1.9 & 2.5 & 13.2084 & 0.0001 \\
\hline Right Lateral Flexion & 39.1 & 42.8 & 3.6 & 1.2 & 1.3 & 13.3155 & 0.0001 \\
\hline Left Lateral Flexion & 39.1 & 42.6 & 3.4 & 1.7 & 1.4 & 11.0140 & 0.0001 \\
\hline
\end{tabular}

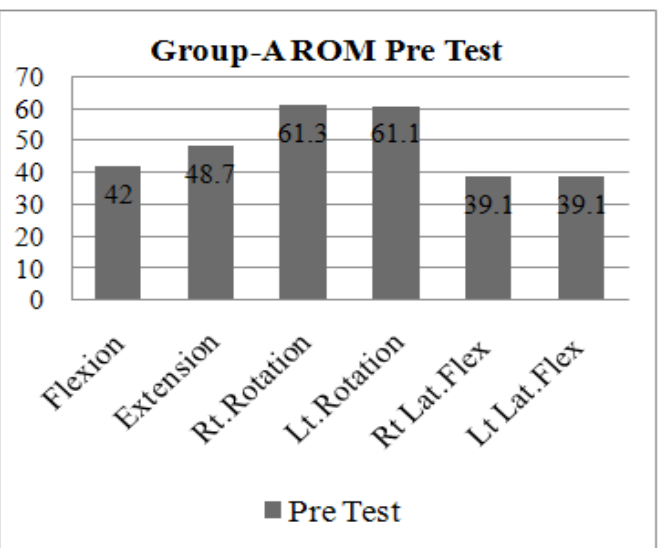

Graph-1.3
Group-A ROM Post Test

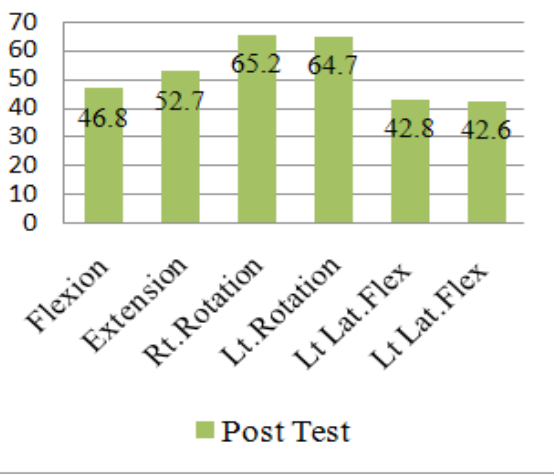

Graph-1.4

Table 2: Shows the significant difference between pre and post-test within the Group A PRT. The paired "t" test shows Flexion mean difference as 4.8 and statistically significant ( $\mathrm{p}=0.0001)$. Mean difference for Extension is 4 and statistically significant $(\mathrm{p}=0.0001)$. Mean difference for Rt Rotation is 3.8 and statistically significant $(\mathrm{p}=0.0001)$. Mean difference for Lt Rotation is 3.6 and statistically significant ( $\mathrm{p}=0.0001)$. Mean difference for Rt Lateral flexion is 3.6 and statistically significant $(\mathrm{p}=0.0001)$. Mean difference for Lt Lateral flexion is 3.4 and statistically significant $(\mathrm{p}=0.0001)$. 
Citation: Seshan J, Selvam S, Sundaram, Suberia S (2020) To Compare the Efficacy of Positional Release Therapy and Muscle Energy Technique in the Management of Unilateral Upper Fibers of Trapezitis. Int J Phys Ther Rehab 6: 163. doi: https://doi.org/10.15344/2455-7498/2020/163

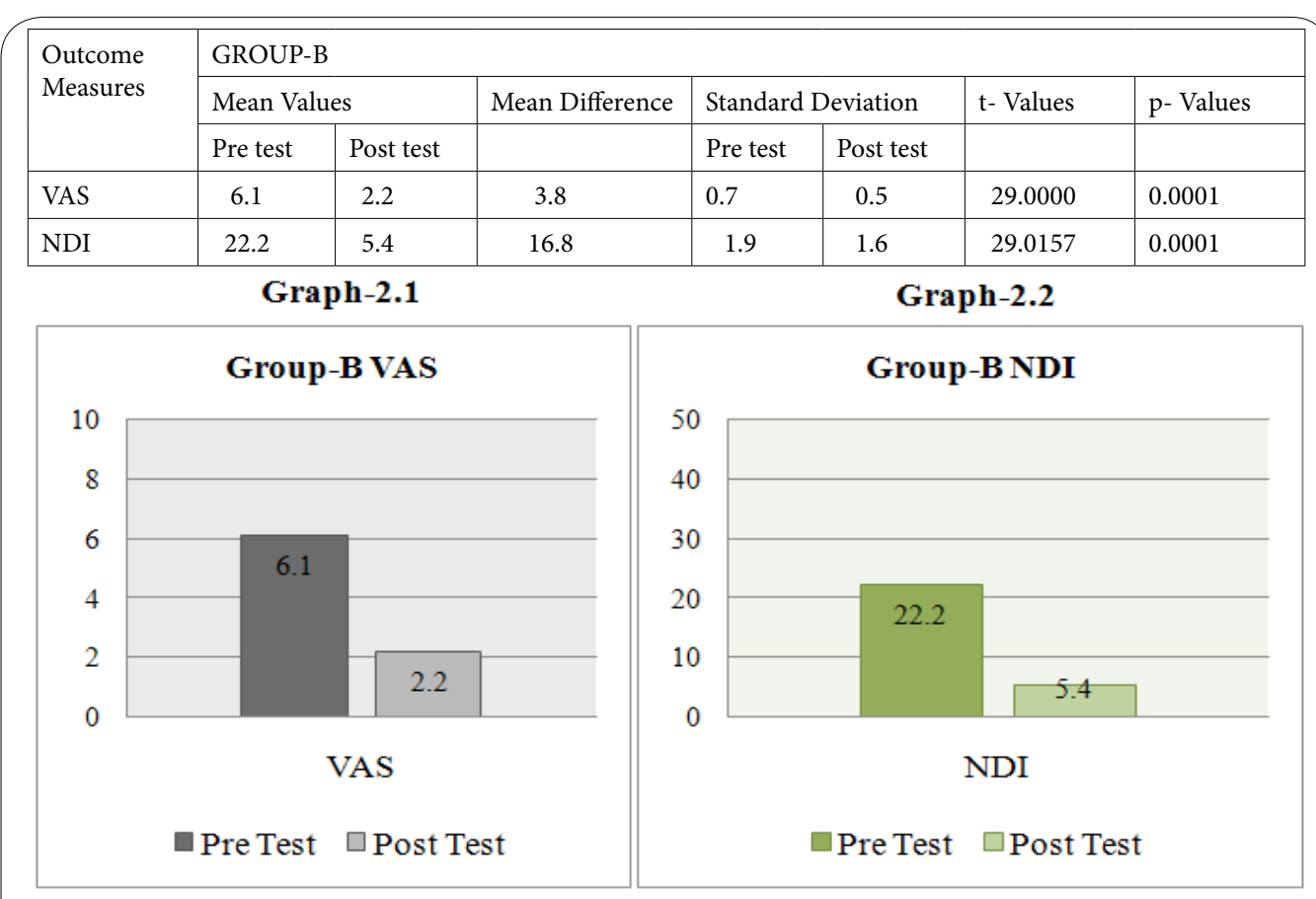

Table 3: Shows the significant difference between pre and post-test within the Group-B MET. The paired " $\mathrm{t}$ " test shows VAS mean difference as 3.8 and is extremely statistically significant $(\mathrm{p}=0.0001)$. Mean difference for NDI score as 16.8 and is extremely statistically significant $(\mathrm{p}=0.0001)$.

\begin{tabular}{|l|c|l|l|l|l|l|l|}
\hline \multirow{2}{*}{ Outcome Measures } & \multicolumn{7}{|c|}{ GROUP-B } \\
\cline { 2 - 8 } & \multicolumn{2}{|l|}{ Mean Values } & Mean Difference & Standard Deviation & t- Values & p- Values \\
\cline { 2 - 8 } & Pre test & Post test & & Pre test & Post test & & \\
\hline Flexion & 42.4 & 46.8 & 4.4 & 2.0 & 2.0 & 16.1436 & 0.0001 \\
\hline Extension & 48.6 & 51.4 & 2.8 & 1.3 & 1.3 & 11.5228 & 0.0001 \\
\hline Right Rotation & 60.4 & 63 & 2.6 & 1.6 & 1.4 & 10.2168 & 0.0001 \\
\hline Left Rotation & 60.2 & 62.6 & 2.4 & 1.0 & 1.2 & 10.4354 & 0.0001 \\
\hline Right Lateral Flexion & 39.4 & 41.8 & 2.3 & 0.9 & 0.6 & 14.6416 & 0.0001 \\
\hline Left Lateral Flexion & 39 & 41.4 & 2.3 & 1.2 & 1.1 & 14.6416 & 0.0001 \\
\hline
\end{tabular}

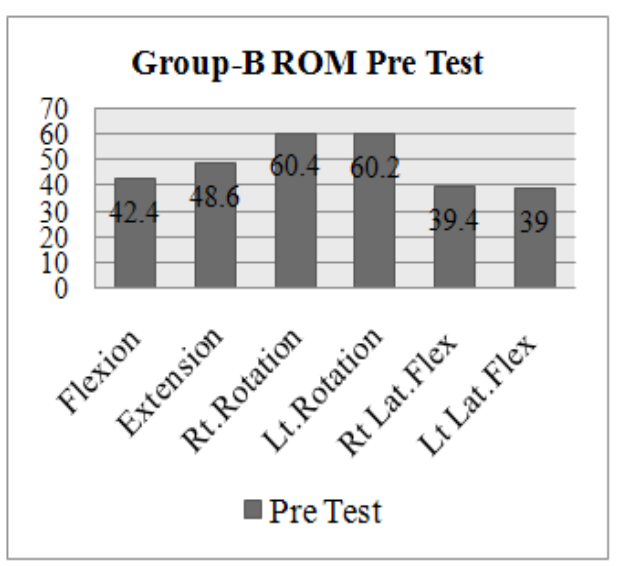

Graph-2.3

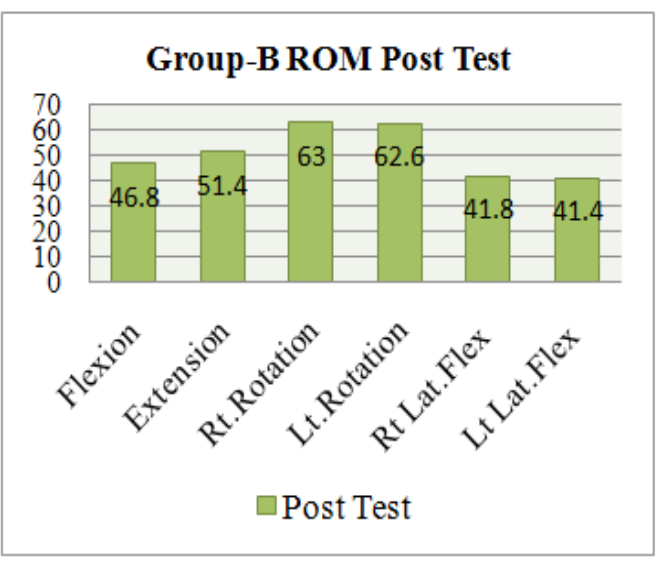

Graph-2.4

Table 4: Shows the significant difference between pre and post-test within the Group B MET. The paired " $\mathrm{t}$ " test shows Flexion mean difference as 4.4 and statistically significant ( $\mathrm{p}=0.0001)$. Mean difference for Extension is 2.8 and statistically significant $(\mathrm{p}=0.0001)$. Mean difference for Rt Rotation is 2.6 and statistically significant $(\mathrm{p}=0.0001)$. Mean difference for Lt Rotation is 2.4 and statistically significant ( $\mathrm{p}=0.0001$ ). Mean difference for Rt Lateral flexion is 2.3 and statistically significant $(\mathrm{p}=0.0001)$. Mean difference for Lt Lateral flexion is 2.3 and statistically significant $(\mathrm{p}=0.0001)$. 
Citation: Seshan J, Selvam S, Sundaram, Suberia S (2020) To Compare the Efficacy of Positional Release Therapy and Muscle Energy Technique in the Management of Unilateral Upper Fibers of Trapezitis. Int J Phys Ther Rehab 6: 163. doi: https://doi.org/10.15344/2455-7498/2020/163

Page 6 of 8

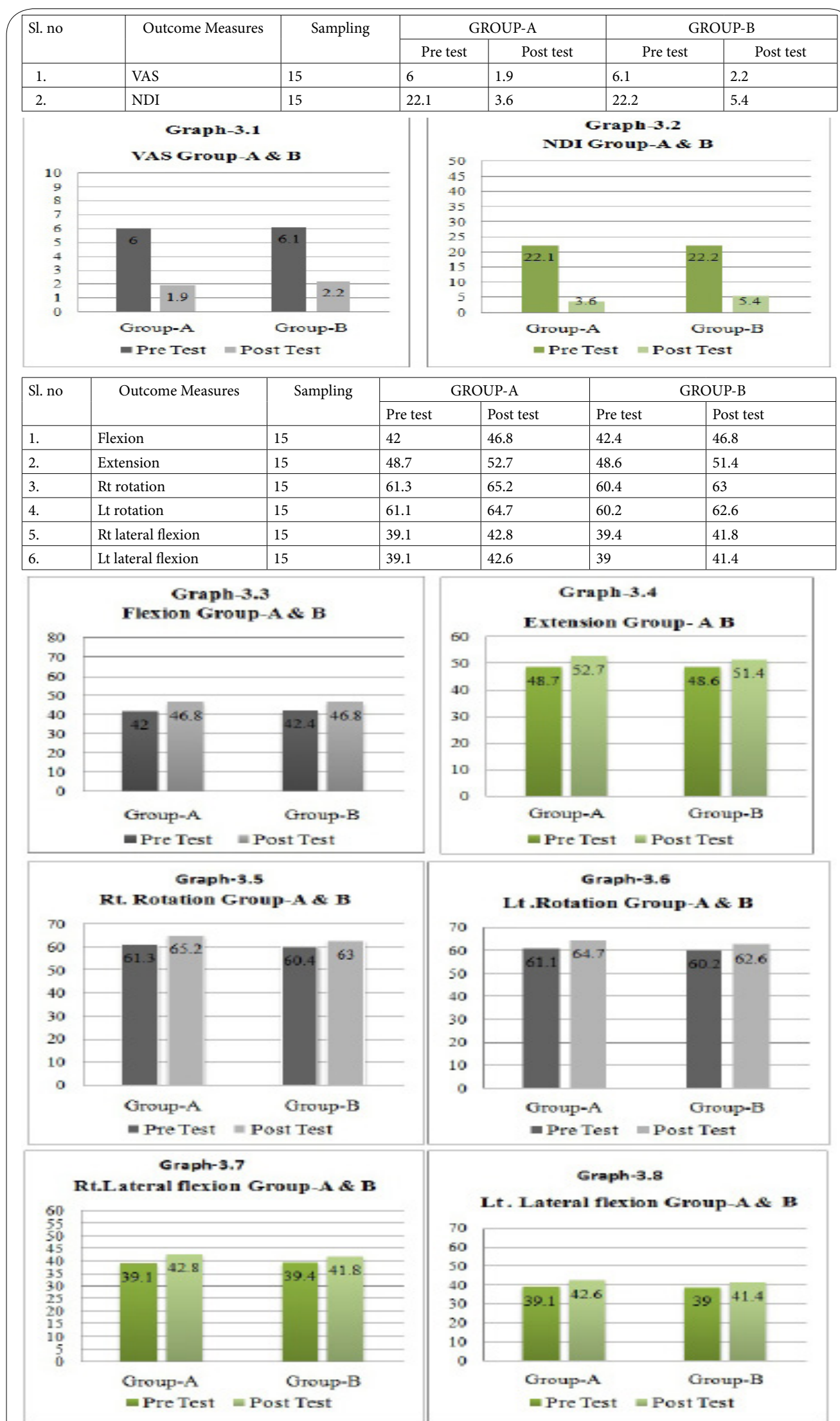

Table 5 and 6: Shows the difference in pain reduction, increase in ROM and improvement in functional activity between group $\mathrm{A}$ and $\mathrm{B}$. 
Citation: Seshan J, Selvam S, Sundaram, Suberia S (2020) To Compare the Efficacy of Positional Release Therapy and Muscle Energy Technique in the Management of Unilateral Upper Fibers of Trapezitis. Int J Phys Ther Rehab 6: 163. doi: https://doi.org/10.15344/2455-7498/2020/163

Page 7 of 8

The mechanism PRT Jones proposed that when a muscle strained by a sudden unexpected force, its antagonist attempts to stabilize the joint, resulting in a counterstrain of the muscle in a resulting or shortened position. The prevailing theory underlying PRT involves placing tissues in a relaxed shortened state, for a period of time $90 \mathrm{~s}$ to decrease gamma gain in order to facilitate restoration of normal tissue length and tension. Based upon in this study statistically significant for VAS score mean difference value is 4.1, NDI mean difference value is 18.6, Flexion mean difference value is 4.8, Extension mean difference value is 4 , Rotation (Rt) mean difference value is 3.8 and Rotation (Lt) is 3.6, Lateral flexion (Rt) mean difference value is 3.6 and Lateral flexion (Lt) is 3.4.

The mechanism MET Fred Mitchell (1948) approach the possible mechanism for the reduction in pain intensity in the MET group can be attributed to the hypoalgesic effects of MET. This can be explained by the inhibitory Golgi tendon reflex, activated during the isometric contraction that leads to reflex relaxation of the muscle. Based upon in this study statistically significant as VAS mean difference value is 3.8, NDI mean difference is 16.7, Flexion mean difference value is 4.4, Extension mean difference value is 2.8, Rotation (Rt) mean difference value is 2.6 and Rotation (Lt) is 2.4 , Lateral flexion (Rt) mean difference is 2.3 and Lateral flexion $(\mathbf{L t})$ is 2.3 .

In this study both techniques shows significant difference in VAS score and NDI questionnaire and ROM of cervical.

From the study, both groups showed improvement in reduction in pain, increase in ROM and improvement in functional ability in the duration of 2 weeks.

The mechanism of PRT is a gentle manual treatment for muscle pain and spasm which involve resetting muscle tone and enhancing circulation states and confirmed by A.Kumareson et al.

Thus, this study validates the use of PRT is improving quality of life and recovery from upper trapezitis.

Subjects treated with PRT showed more significant improving in pain reduction, increasing cervical ROM and improving in functional ability when compared with MET.

\section{Conclusion}

In this study provided evidence to support the use of PRT and MET in management for upper trapezitis. This study concludes that PRT is more effective in relieving cervical pain, restoration of cervical ROM and prevent neck disability when compared with MET for unilateral upper fibers of trapezitis.

\section{Limitation}

1. Even if the study limitations regarding small sample size.

2. The study findings limited by the short-term duration.

3. Only upper fibers of trapezitis was taken.

4. Neck pain along with trigger point were included.

\section{Recommendation}

1. Greater sample size is recommended.
2. Longer duration by taking long lasting effects of treatment in follow up assessment.

3. Giving intervention to other group of neck muscle can be included.

\section{Acknowledgment}

The author acknowledge God, family, study participants; Dr. Jyoti Seshan, Dr. P. Senthil Selvam and Dr. Priya Kumari who helped make this process successful.

\section{Competing Interests}

The authors declare that they have no competing interests.

\section{References}

1. Karthick K (2017) A study on the Effectiveness of Positional Release Therapy in the Management of Trapezitis. Journal of Computational Biology 6: 1925.

2. Joshi R, Rathi M (2015) Effect of muscle energy technique versus positional release technique on pain and functions in patients with trapezitis- $A$ comparative study. International Journal of Science and Research.

3. Carvalho SC, Babu KV, Kumar NS, Ayyappan VR (2014) Effect of positional release technique in subjects with subacute trapezitis. Int J Physiother 1 : 91-99.

4. Rana PD, Brahmbhatt B (2017) Effect of muscle energy technique versus positional release technique in computer workers with upper trapezius muscle spasm: A comparative study. International Journal of Multidisciplinary Research and Development 4: 29-35.

5. Mahajan R, Kataria C, Bansal K (2015) Comparative Effectiveness of Muscle energy Technique and Static Stretching for Treatment of Subacute Mechanical Neck Pain.

6. Basak T, Pal TK, Sasi M, Agarwal S (2018) A Comparative Study on the Efficacy of Ischaemic Compression and Dry Needling with Muscle Energy Technique in Patients with Upper Trapezius Myofascial Trigger Points. International Journal of Health Science and Research.

7. Wakde P, Anap D (2016) Effectiveness of integrated neuromuscular inhibitory technique in sub-acute trapezitis: A single case study. VIMS Physiotherapy Journal of Case Reports 1: 11-15

8. Jhaveri A, Gahlot P (2018) Comparision of effectiveness of myofascial release technique versus muscle energy technique on chronic trapezitis An Experimental study. International Journal of Innovative Research and Advanced Studies 5: 2394-4404.

9. Mense S, Simons DG (2000) Muscles pain understanding its nature Diagnosis and treatment. Philadelphia, Lipincott Williams and Wilkins.

10. Ambrogio KD, Roth G (1997) Positional Release Therapy.

11. Jones LH (1995) Jones Strain Counterstrain.

12. Travell JD, Simons DG (1983) Myofascial Pain and Dysfunction: The Trigger point Manual.

13. Nagrale AV, Glynn P, Joshi A, Ramteke G (2010) The efficacy of an Integrated neuromuscular inhibition technique on upper trapezius trigger points in subjects with non-specific neck pain: a randomized controlled trial. J Man Manip Ther 18: 37-43.

14. Hong CZ, Simos DG (1998) Pathophysiologic and Electrophysiologic mechanisms of myofascial trigger points. Arch Phys Med Rehabilitation 79: 863-872.

15. Chung JW, Ohrbach R, McCall WD (2004) Effect of increased sympathetic activity on electrical activity from myofascial painful areas. Am J Phys Med Rehabilitation 83: 842-850.

16. Chaitow L (2001) Muscle Energy Technique. Edinburgh: Churchil Livingstone.

17. Chaitow L (2005) Muscle Energy Techniques. Edinburgh: Churchill Livingstone. 
Citation: Seshan J, Selvam S, Sundaram, Suberia S (2020) To Compare the Efficacy of Positional Release Therapy and Muscle Energy Technique in the Management of Unilateral Upper Fibers of Trapezitis. Int J Phys Ther Rehab 6: 163. doi: https://doi.org/10.15344/2455-7498/2020/163

Page 8 of 8

18. Nambi GS, Sharma R, Inbasekaran D, Vaghesiya A, Bhatt U, et al. (2013) Difference In Effect Between Ischemic Compression And Muscle Energy Technique On Upper Trapezius Myofascial Trigger Points: Comparative study. Int J Health Allied Sci 2: 17-22.

19. Mahajan R, Kataria C, Bansal K (2012) Comparative Effectiveness of Muscle Energy Technique and Static Stretching for Treatment of Subacute Mechanical Neck Pain. Int J Health Rehabil Sci 1: 16-24. 